\title{
DISTANCE LEARNING AND COVID-19 FROM STUDENTS' PERSPECTIVE: DO THEY HAVE THE SKILLS TO DEAL WITH THE UNPRECEDENTED SITUATION?
}

\author{
Liena Hačatrjana \\ University of Latvia, Latvia
}

\begin{abstract}
As a result of the COVID-19 pandemic, more than 1,6 billion children worldwide were forced to discontinue face-to-face education and continue with distance learning (OECD, 2020). To many students as well as teachers this was their first experience with distance learning. Students' ability to adapt to distance learning varies and depends on different factors, including individual factors such as the ability to cope with new situations, solve problems and manage their own learning process. In order to successfully deal with the new circumstances in education, it is necessary to work at all levels - including the level of policy development, level of schools as organizations, and at the individual - the student - level. This article focus on the level of the students and look on the distance learning from the perspective of students' skills, attitudes and ability to adapt to the situation. The aim of this article is to summarize what has been studied so far in different countries about COVID-19 related distance learning and students' difficulties and ability to cope with this situation; and to suggest practices to develop students' skills such as self-management and problem-solving skills to better adapt to new situations in the future.
\end{abstract}

Keywords: students, adolescence, COVID-19, distance learning, problem-solving skills, selfmanagement skills.

\section{Introduction}

COVID-19 pandemic has created pressure on all sorts of domains of life, including mental and physical well-being of individuals, as well as stability of industries and economics of countries. For students, it has brought up the challenge to maintain their academic performance and motivation to study, to continue with receiving their education and to maintain psychological and physical well-being above all that. A simulation research issued by World Bank has warned about increasing inequality among students that may escalate even further because of pandemic, and for the most vulnerable groups of children it may even lead to discontinuing their education (Azevedo et al., 2020). Simulations also show that school closures could lead to a loss of learning in amount of at least one school year, and there is a risk that children will have 
hardship keeping up with the curriculum also after returning to schools and faceto-face learning (Kaffenberger, 2021), therefore policy makers and schools are advised to plan in advance on how to help children after returning to schools, and how to strengthen their abilities and skills. The aim of this article is to summarize currently available research about students' difficulties and ability to cope with the distance learning during COVID-19 pandemic, and to suggest practices to develop students' skills such as self-management and problem-solving skills to better adapt to such unprecedented situations. The research methods included analysis of literature and research reports, by searching in the publications' databases.

\section{Challenges in Education during Pandemic}

A report published by the OECD emphasizes the need to strengthen resilience at all three levels: the level of systems, the level of schools and the level of individuals, together creating a strong, cohesive ecosystem (OECD, 2020). Various suggestions can be found on how to organize distance learning at school level, as well as methodological advice for teachers (e.g., issued by state agencies). However, there is a lack of studies published (at the moment of drafting this article) on actual assessment of skills (e.g., problem-solving skills or selfmanagement) of students during COVID-19. The preservation of the quality of education is sometimes discussed at the political level from the position of "teaching", not "learning", focusing on strengthening the capacity of the school as an organization and teachers' capacity, as the "first aid" during such pandemic is to come up with ideas as to how to maintain studying process remotely and implement these ideas immediately, as many countries have done.

As mentioned above, it is equally important to strengthen the individual level during the pandemic. A "resilient individual" is defined by the ability to accept changes and uncertainty, having confidence in one's skills and critical thinking skills (OECD, 2020). With COVID-19 pandemic developing, public resources in some countries were very soon available with recommendations for pupils and students on how to manage their distance learning and maintain their psychological well-being (e.g. in Australia, https://schools.au.reachout.com/ covid-19). Students were also offered various online modules to learn about specific skills, such as self-efficacy, flexibility in thinking, how to cope with learning stress during COVID-19 and other important topics. UNESCO and the World Health Organization (WHO) have published various support materials on distance learning, mental health and other issues relevant to the healthy functioning of people due to the changes brought about by COVID-19 (e.g., https://en.unesco.org/covid19/educationresponse/solutions; WHO, 2020, https://www.who.int/docs/default-source/coronaviruse/mental-health- 
considerations.pdf). There are also digital self-help tools and applications available that can help with self-management and problem-solving skills. However, if self-management skills have not been trained before the crisis, it could be hard to individually and independently initiate development of such skills via online learning, especially for young students whose self-regulation skills are only in the development process and if such skills have not been systematically developed in school before.

Data from 98 countries were gathered about the response of the national level and school level to COVID-19 related education disruption (Reimers \& Schleicher, 2020). Most countries reported that ensuring the continuity of academic learning for students, supporting the students who lack skills for independent study, ensuring the well-being of students and of teachers are challenging and they are important issues that must be dealt with. Also, majority of respondents optimistically share an opinion that distance learning might lead to increase in the autonomy of students to manage their own learning. This article by Reimers and Schleicher also highlights some data from PISA2018 study regarding students' home settings for studying, and it shows that on average $91 \%$ of students have a quiet place at home for schoolwork and 34\% to 95\% have a computer they can use for studying (based on OECD PISA 2018 database). Numbers may seem high, but they also mean that there are enough children who do not have appropriate home settings for effective studying remotely. Once again, it puts such children at risk for increasing inequality, both by decreasing their ability to keep up with the curriculum during and after the pandemic, and at risk of decrease in well-being, as stated in other reports (Azevedo et al., 2020).

Distance learning during the pandemic increases the risk of decline in academic performance, and schools and policy makers must think in advance about how to mitigate the losses in education (Kaffenberger, 2021). In a UNESCO publication "Guidance on Active Learning at Home during Educational Disruption: Promoting student's self-regulation skills in COVID-19 outbreak" (Huang et al., 2020) there is a call for students to become active learners during the distanced learning. But it can be harder for students whose self-regulation skills are lower at baseline and for those who lack external support from their family. Students need to develop self-management skills, including planning skills, self-monitoring and problem-solving skills to be active learners and to be able to manage their own learning. Therefore, it is essential, that students learn strategies of self-management and problem-solving to effectively engage in distance learning due to COVID-19 or other unexpected situations that might come in the future. 
Hačatrjana, 2021. Distance Learning and COVID-19 from Students'Perspective: Do They Have the Skills to Deal with the Unprecedented Situation?

\section{Research on Students' Skills and Attitudes during the COVID-19 Related Distance Learning}

Once the COVID-19 pandemic developed, researchers, as well as official institutions, started implementing research and suggesting recommendations regarding difficulties that students were facing with distance learning process, various aspects of psychological well-being and other problems related to pandemic (e.g., WHO, 2020; Singh et al. 2020).

The research was done at a country level and internationally. For example, The Ministry of Education and Science of Latvia immediately after the start of distance learning (spring of 2020) launched an online survey to understand how distance learning was perceived by schools, pupils and parents, and what improvements were needed; survey was completed by more than 23,000 children and 27,000 parents (Latvia has a population of 1, 92 million people in 2019). The initial survey showed that $55 \%$ of parents supported the child by helping him or her plan their time (because the child needed help with it) (Ministry of Education and Science of Latvia, 2020). The study found that some students had difficulty in distance learning due to the lower work pace and lack of face-to-face support from the teacher, while other students liked to be able to plan their own time and prioritize. In a similar survey at the end of study year (after more than 2 months of distance learning), students were asked "What helped you study successfully during the distance learning?” and $57 \%$ of students $(n=9930)$ reported that the family supported their learning, 55\% noted that they could sleep for longer (and it helped), and 51\% chose also the option "I could plan my daily schedule". Interestingly, 26\% of students reported that it was easier for them to study alone, compared to learning in the classroom settings. Students were also asked: "What were the biggest challenges for you during distance learning?” and $45 \%$ reported they had stress whether they would manage to do all assignments on time $(n=10,051), 42 \%$ reported lack of motivation, and $29 \%$ chose also the answer option "It was harder to study alone" (IZM, 2020). The various results point to a gap between different students' ability to cope with distance learning and overall attitude, which may be not only due to lack of family support or environment, but also due to differences in students' transversal skills, such as ability to manage themselves effectively and to deal with problem situations that arise during this new situation, and their psychological well-being.

There are studies that have focused on psychological and other difficulties of students during COVID-19 pandemic. A qualitative analysis of high school students' self-reports $(n=719)$ on the challenges they are facing during COVID19 pandemic summarizes important categories of students' problems: 1) mental health, 2) physical health, 3) family, 4) friends, 5) social connection and community, 6) academics, 7) missing important events, 8) socioeconomic issues, 
9) routine, 10) COVID rules and adjustment, 11) contraction/exposure to COVID, 12) technology, and 13) future plans (Scott et al., 2020). Challenges related to studying were mentioned most frequently, including difficulty to stay motived, productive and manage one's time; followed by challenges with mental and physical health. Another study compared students' mental health measures before and during the pandemic ( $n=406$, age $M=15,24)$ using valid inventories for assessment of depression symptoms, affect, as well as other measures, and it was found that both anxiety, loneliness and depression symptoms show small, but statistically significant increase (Rogers, Ha \& Ockey, 2021). Also, this study reported changes in students' relationship dynamics with friends and family, indicating challenges in their socio-emotional functioning.

There are also studies with university students showing that a certain part of students find distance learning as effective as face-to-face learning, at the same time reporting difficulties (69\%), such as loss of interest and fatigue (67\%) and have also reported less gain of knowledge compared to traditional education (e.g., Tuma et al., 2021); also, an international study with 26 participating countries (Van de Velde et al., 2021) has taken place, investigating university student wellbeing and comparative results are yet to be published. In another study during COVID-19 distance learning, first-year undergraduates reported that they had hard time with discussions and conversations with lecturers and classmates, while distance learning gave them more time to read the materials themselves and to do their individual homework (Amir et al., 2020). Interestingly, more than half of the students (tertiary education level) noted that distance learning increased selfdirected learning, for example, it motivated to carefully prepare for group discussions. Authors discuss that satisfaction with distance learning could be also related to students' age and level of education: whether they are learning introductory theory or need practicing specific professional skills at that point of studies, which is particularly difficult during the distance learning process.

The time elapsed since the beginning of the pandemic has not probably been long enough for a vast number of scientific studies to be caried out and published in peer-reviewed journals, but in general, the amount of various materials and first results of research is what we can analyze to draw first conclusions. Currently there is a lack of research involving secondary and high-school students, especially with assessment of students' skills and abilities. OECD has published an extensive survey tool for a comprehensive assessment of the distance learning situation “The PISA Global Crises Questionnaire Module” (Bertling et al., 2020), based on which we could eventually gain comparable data from many countries of the world. The limitation with some of the currently available research is that they do not show the full picture of psychological constructs (e.g., depression, anxiety) and rarely measure students' skills and abilities; some conclusions are based on single question measurements. While the large-scale international 
studies can provide comparison of the situation in different countries, it is also important to study the situation in each country and to also focus on specific domains such as aspects of psychological well-being, socio-emotional skills, problem-solving skills and self-management skills to help students develop the ability to deal with such unprecedented situations in the future.

To conclude, studies in different countries show that students face serious difficulties in many domains during pandemic, including psychological functioning and learning, indicating there is a lack of certain skills and received support. It can be concluded that distance learning and the new, unprecedented situation in general impose that students now more than ever need the ability to manage themselves and their learning, as well as to deal with novel situations and everyday problems.

\section{Developing Skills to Effectively Deal with Unprecedented Situations}

Global reports stress the need to develop students' skills, for example, socioemotional skills, problem-solving skills and self-management skills (World Bank, 2020). This article focuses mostly on problem-solving and self-management skills of students. But how do we define problem-solving and self-management, and what exactly students must develop?

Problem solving is defined as a process that occurs when an individual encounters a problem (or a goal) that cannot be achieved immediately by a particular action, instead one must use thinking to understand how to get from the current state to the goal state (Duncker, 1945). Doing an automated task is not considered problem-solving, however, dealing with an unprecedented situation is considered problem solving. Researchers have further developed the definition: problem-solving as a process involves multiple thought operations and actual activities (Frensch \& Funke, 1995). The international education survey PISA defines problem-solving as the ability of an individual to use cognitive processes to understand and resolve real, interdisciplinary situations where the solution is not immediately apparent and where the knowledge is not limited to only one of the core fields of mathematics, reading or science (OECD, 2003; OECD, 2013). Problem solving skills are transversal skills (they can be applied to various situations in various domains) and the problem-solving process involves managing and directing actions to cope with a problem toward changing the nature of the situation, changing the reaction to the problem, or both (Nezu, 2004). Problem-solving consists of main processes: 1) exploration and understanding; 2) representation and formulation; 3) planning and executing; 4) monitoring and reflecting (OECD, 2013).

Self-management is a part of self-regulated learning, defined by the ability to 1) plan, 2) monitor and 3) evaluate (Zimmerman, 2008). Self-regulated learning 
includes skills that provide ability to manage one's actions regarding learning. The individual thinks about one's learning needs, plans them, then monitors the process, directs and regulates actions toward goals of information acquisition, expanding expertise, and self-improvement. A student with highly developed selfmanagement skills is able to motivate oneself, plan tasks, as well as evaluate the results (Veenman et al., 2014). We can see that both problem-solving and selfmanagement share some similar underlying processes.

Research results indicate that both problem-solving and self-management skills are important to succeed academically. Problem solving skills have strong correlations to different types of cognitive abilities (e.g., Danner, Hagemann, Schankin, Hager, \& Funke 2011; Kretzschmar et al., 2016) and academic achievement (e.g., Greiff, Kretzschmar, Müller, Spinath, \& Martin, 2014; Greiff, Wüstenberg, Molnár, Fischer, Funke, \& Csapó, 2013). Self-management skills have also been shown to be significantly correlated with academic performance, as they are a strong predictor for learning outcomes (e.g., Abd-El-Fattah, 2010; Veenman et al., 2014).

How can the development of self-management (an important part of selfregulated learning) and problem-solving skills help students to better deal with the current crisis and its aftermath? First, there are two issues to consider: 1) how to support development of students' skills during the distance learning and 2) how to develop their skills after the return to face-to-face learning?

Regarding the first issue, it must be considered what kind of distance learning approach is used during the pandemic. There are different types of distance learning, for example, synchronous, asynchronous and blended learning, where the methods are mixed (Fidalgo, Thormann, Kulyk, \& Lencastre, 2020). There were different approaches used in countries around the world (Reimers \& Schleicher, 2020), based on available infrastructure and other factors (for example, in case of bad internet coverage or lack of computers, teachers could distribute printed materials with tasks). In Latvia, various forms of learning were implemented in the distance learning process during the pandemic, for example, teachers organized both online video lessons at a specified time (synchronously) and recorded videos with lesson content or videos with comments on frequently asked questions that students can watch at their preferred time (asynchronously), as well as gave students written or practical tasks (Ministry of Education and Science of Latvia, 2020).

In an article analyzing online tools for assessment and development of selfregulated learning it is discussed that online approach can be effective and can include methods for raising metacognition, for example, when student is asked to stop at a certain point of task and reflect what has been done so far (for detailed analyses see Araka et al., 2020). In another recent article researchers analyze appropriate approaches for self-regulated learning while studying remotely and 
they note that students under stress (such as pandemic) might have difficulties with self-directed learning as they must be aware of what they do know and do not know and independently make decisions about what exactly must be done; also, the use of artificial intelligence tools to assist learners is discussed (see Carter et al., 2020 for a detailed analysis).

Regarding the second issue (how to develop students' skills after they return to face-to-face learning) it is important to assess students' skills during and after the pandemic, including assessment of difficulties they had during the distance learning. Also, it has to be understood how transversal skills can be best taught, in general. As research show, transversal skills can be most effectively developed if 1) teachers explicitly talk about what is being done and why (e.g., "First, we have to understand the task to the smallest detail: what concepts are included in this problem?", "Now we will try to come up with several possible solutions so we can choose the most appropriate."), and give feedback to students; and if 2) the development of skills is a part of curriculum or a certain field of action, not being taught independently without a context (e.g., Perels, Guertler, \& Schmitz, 2005). And in this case, if a student has not previously trained a skill of problemsolving, one might not recognize when it needs to be used, and what exact steps to follow. Recognizing when to use a skill, being aware of it, and training (using) a skill is necessary to develop it to a profound level. The unprecedented situation during pandemic demanded students to use self-management and problemsolving skills at the level they had at that moment, for example, they were forced to plan and execute school tasks independently, to use new technologies (with or without support from family) without a teacher being there to support. And, based on the research discussed previously, students had problems with this, indicating that students' problem-solving skills and self-management skills were insufficient when they entered the distance learning situation (for example, in Latvia students have previously showed only average results in the ability to cope with nonstandard situations in one of previous PISA studies (OECD, 2017)). It is still unclear to what extent these important skills could be developed during the pandemic, as longitudinal research have to be caried out to examine this point.

To sum up, we can assume that both self-management skills and problemsolving skills are essential for students to achieve high academic performance and to successfully engage in learning process. And schools must think in advance about methods how to help students develop these skills also after the pandemic. Feedback from teachers and training the self-reflection can be some methods to start with (Carter et al., 2020) that can be implemented online if the distance learning continues or in face-to-face learning after students return to schools. It is best if teachers integrate a specific sub-skill into daily activities of teaching a certain field and explicitly talk about the skills that are being trained. 


\section{Conclusions}

It is clear from the studies that have been published at the point of preparing this article that students worldwide have faced many challenges during COVID19 related distance learning, and they were forced to adapt to this unprecedented situation in ways that they could. Studies show that students have had difficulties in dealing with the new situation based on lack of certain skills, e.g., selfmanagement skills and problem-solving skills, as well as lack of support. Additionally, worldwide organizations have warned about the risks of learning challenges in the future for the students currently affected by the pandemic. It is crucial to think about the possible means of strengthening students' ability to cope with the situation while they are learning remotely, as well as when they return to face-to face learning.

Ability to deal with this unprecedented situation and its aftermath can be associated to many factors, including socio-economic situation and environment, external support from family, and students' skills (the individual factor attributed to students). As can be concluded from the research, the main skills that students need to effectively deal with the situation can be arranged in several categories: social-emotional skills, self-management skills, problem-solving skills, technical (IT skills) and others. As stated in the introduction, this article focused mostly on the research of two of the abovementioned skills: ability to solve problems and manage oneself.

Based on the literature analysis it can be concluded that there is a certain overlap between the constructs "self-management skills" and "problem-solving skills" in the theory - especially with regard to cognitive processes that manifest in the case of both skills, such as planning, monitoring and evaluation. But the main difference is that self-management skills are manifested in the ability to cope with one's own "internal problems" or to "manage oneself”, including motivating, planning one's time, goal setting, the ability to avoid obstacles, focus and successfully implement the set tasks, and to analyze oneself during and after the whole process. In turn, problem-solving skills include the ability to deal also with various "external problems", everyday situations, challenges, such as using a new technology, creating an appropriate learning environment, choosing priorities from incoming tasks (by evaluating them and making decisions), as well as solving relationship problems and communicating effectively (with peers, with teachers, etc.), to plan time and other resources, to involve other people in team work, and also be able to initially explore and precisely define where the problem is. As mentioned in the previous section, self-management skills are a part of selfregulated learning, thus they are important to effectively engage in the learning process, especially during distance learning. 
Hačatrjana, 2021. Distance Learning and COVID-19 from Students'Perspective: Do They Have the Skills to Deal with the Unprecedented Situation?

Also, it must be noted that self-management and problem-solving skills refer to a broader scope of individual's functioning (e.g., daily life), not only schoollearning. Therefore, they are both important transversal skills that are necessary to cope with novel situations, and they can be developed as a part of curriculum via online learning (if remote learning continues), or during face-to-face learning. Nevertheless, guidance and support from teachers during the development of these skills is crucial, especially for those students who lack the resilience, selfmanagement skills, or support from parents (Reimers \& Schleicher, 2020).

Research show that students have faced serious difficulties in dealing with the pandemic, therefore indicating that their skills to deal with novel situations and such pressure are not sufficient. Thus, the next research question arises: "How can we help students deal with the aftermath of COVID-19 when they return to face-to-face learning?" and "How can their skills be strengthened and developed further to better deal with unprecedented situations in the future?"

\section{Acknowledgment}

The research reported here is supported by EU "Post-doctoral Research Aid" project „Relationship between students’ self-management and problem-solving skills and changes in academic achievement during face to face and distance learning situations”, Nr. 1.1.1.2/VIAA/4/20/697.

\section{References}

Abd-El-Fattah, S. (2010). Garrison's Model of Self-Directed Learning: Preliminary Validation and Relationship to Academic Achievement. The Spanish Journal of Psychology, 13(2), 586-596. doi:10.1017/S1138741600002262

Amir, L. R., Tanti, I., Maharani, D. A., Wimardhani, Y. S., Julia, V., Sulijaya, B. \& Puspitawati, R. (2020). Student perspective of classroom and distance learning during COVID-19 pandemic in the undergraduate dental study program Universitas Indonesia. BMC Medical Education, 20, 392. https://doi.org/10.1186/s12909-020-02312-0

Araka, E, Maina, E., Gitonga, R, and Oboko, R. (2020). Research trends in measurement and intervention tools for self-regulated learning for e-learning environments-systematic review (2008-2018). Research and Practice in Technology Enhanced Learning, 15 (6). https://doi.org/10.1186/s41039-020-00129-5

Azevedo, J. P., Hasan, A., Goldemberg, D., Iqbal, S. A., \& Geven, K. (2020). Simulating the Potential Impacts of COVID-19 School Closures on Schooling and Learning Outcomes: A Set of Global Estimates. Policy Research Working Paper, No. 9284. World Bank, Washington, DC.

Bertling, J., Rojas, N., Alegre, J., \& Faherty, K. (2020). A tool to capture learning experiences during Covid-19: The PISA Global Crises Questionnaire Module, OECD Education Working Papers, No. 232, OECD Publishing, Paris, https://doi.org/10.1787/9988df4e-en 
Carter, Jr, R. A., Rice, M., Yang, S., \& Jackson, H. A. (2020). Self-regulated learning in online learning environments: strategies for remote learning. Information and Learning Sciences, 121 (5/6), 321-329. https://doi.org/10.1108/ILS-04-2020-0114

Danner, D., Hagemann, D., Schankin, A., Hager, M., \& Funke, J. (2011). Beyond IQ. A latent state trait analysis of general intelligence, dynamic decision making, and implicit learning. Intelligence, 39, 323-334.

Dardary, O., Daaif, J., Tridane, M., \& Belaaouad, S. (2020). Distance learning in the age of COVID-19: Between Perspective and Reality. International Journal of Engineering Applied Sciences and Technology, 5 (5), 46-52.

Duncker, K. (1945). On problem-solving. Psychological Monographs, 58, i-113. doi:10.1037/h0093599

Frensch, P. A., \& Funke, J. (1995). Definitions, Traditions and a General Framework for Understanding Complex Problem Solving. In P. A. Frensch \& J. Funke (Eds.) Complex Problem Solving: the European Perspective (pp.3-26). New York: Lawrence Erlbaum Associates.

Greiff, S., Kretzschmar, A., Müller, J. C., Spinath, B., \& Martin, R. (2014). The ComputerBased Assessment of Complex Problem Solving and How It Is Influenced by Students' Information and Communication Technology Literacy. Journal of Educational Psychology, 106 (3), 666-680. doi: 10.1037/a0035426

Greiff, S., Wüstenberg, S., Molnár, G., Fischer, A., Funke, J., \& Csapó, B. (2013). Complex problem solving in educational contexts-Something beyond g: Concept, assessment, measurement invariance, and construct validity. Journal of Educational Psychology, 105 (2), 364-379.

Huang, R.H., Liu, D.J., Amelina, N., Yang, J.F., Zhuang, R.X., Chang, T.W., \& Cheng, W. (2020). Guidance on Active Learning at Home during Educational Disruption: Promoting student's self-regulation skills during COVID-19 outbreak. Beijing: Smart Learning Institute of Beijing Normal University.

Kaffenberger, M. (2021). Modelling the long-run learning impact of the Covid-19 learning shock: Actions to (more than) mitigate loss. International Journal of Educational Development, 81. https://doi.org/10.1016/j.ijedudev.2020.102326

Kretzschmar, A., Neubert, J. C., Wüstenberg, S., \& Greiff, S. (2016). Construct validity of complex problem solving: A comprehensive view on different facets of intelligence and school grades. Intelligence, 54, 55-69. http://doi.org/10.1016/j.intell.2015.11.004

IZM [Ministry of Education and Science of Latvia]. (2020). Attālinātās mācības no skolènu, skolotāju un vecāku skatupunkta. Published on 14.07.2020. Retrieved from https://www.izm.gov.lv/lv/jaunums/attalinatas-macibas-no-skolenu-skolotaju-unvecaku-skatupunkta-1

Nezu, A. M. (2004). Problem solving and behavior therapy revisited. Behavior Therapy, 35(1), 1-33. https://doi.org/10.1016/S0005-7894(04)80002-9

OECD. (2003). PISA 2003 Assessment Framework: Mathematics, Reading, Science and Problem Solving Knowledge and Skills. Paris: The organisation for Economic Cooperation and Development.

OECD. (2013). PISA 2012 Assessment and Analytical Framework: Mathematics, Reading, Science, Problem Solving and Financial Literacy, PISA, OECD Publishing, Paris. https://doi.org/10.1787/9789264190511-en.

OECD. (2017). PISA 2015 Results (Volume V): Collaborative Problem Solving, PISA, OECD Publishing, Paris. https://doi.org/10.1787/9789264285521-en. 
Hačatrjana, 2021. Distance Learning and COVID-19 from Students'Perspective: Do They Have the Skills to Deal with the Unprecedented Situation?

OECD. (2020). Lessons for Education from COVID-19: A Policy Maker's Handbook for More Resilient Systems, OECD Publishing, Paris. https://doi.org/10.1787/0a530888-en. Retrieved from http://www.oecd.org/education/lessons-for-education-from-covid-190a530888-en.htm

Perels, F., Gürtler, T., \& Schmitz, B. (2005). Training of self-regulatory and problem-solving competence. Learning and Instruction, 15(2), 123-139. https://doi.org/10.1016/j.learninstruc.2005.04.010

Reimers, F. M., \& Schleicher, A. (2020). A framework to guide an education response to the COVID-19 Pandemic of 2020. OECD. Retrieved from https://globaled.gse.harvard.edu/files/geii/files/framework_guide_v1_002.pdf

Rogers, A. A., Ha, T., \& Ockey, S. (2021). Adolescents' Perceived Socio-Emotional Impact of COVID-19 and Implications for Mental Health: Results From a U.S.-Based MixedMethods Study. Journal of Adolescent Health, 68, 43-52.

Scott, S. R., Rivera, K. A., Rushing, E., Manczak, E. M., Rozek, C. S., \& Doom, J. R. (2020). "I Hate This": A Qualitative Analysis of Adolescents' Self-Reported Challenges During the COVID-19 Pandemic. Journal of Adolescent Health, 1-8. https://doi.org/10.1016/j.jadohealth.2020.11.010

Singh, S., Roy, D., Sinha, K., Parveen, S., Sharma, G., \& Joshi, G. (2020). Impact of COVID19 and lockdown on mental health of children and adolescents: A narrative review with recommendations. Psychiatry Research, 293. https://doi.org/10.1016/j.psychres.2020.113429

Tuma, F., Nassar, A. K., Kamel, M. K., Knowlton, L. M., \& Jawad, N. K. (2021). Students and faculty perception of distance medical education outcomes in resource-constrained system during COVID-19 pandemic. A cross-sectional study. Annals of Medicine and Surgery. https://doi.org/10.1016/j.amsu.2021.01.073.

Van de Velde, S., Buffel, V., Bracke, P. F. et al. (2021). The COVID-19 International Student Well-being Study, Scandinavian Journal of Public Health. DOI: 10.1177/1403494820981186

Veenman, M. V. J., Hesselink, R. D., Sleeuwaegen, S., \& Liem, S. I. E. (2014). Assessing Developmental Differences in Metacognitive Skills With Computer Logfiles: Gender by Age Interactions. Psychological Topics 23(1), 99-113.

World Bank. (2020.) The COVID-19 Pandemic: Shocks to Education and Policy Responses, Published on $2020 . \quad$ Retrieved from https://openknowledge.worldbank.org/bitstream/handle/10986/33696/148198.pdf

World Health Organization. (2020). COVID-19: resources for adolescents and youth. World Health Organization. Retrieved from http://www.who.int/maternal_child_adolescent/links/covid-19-mncah-resourcesadolescents-and-youth/en/.

Zimmerman, B. J. (2008). Investigating self-regulation and motivation: historical background, methodological developments, and future prospects. American Educational Research Journal, 45 (1), 166-183. 